Saeedi, Z., Ziaee, M. (2020): Biochemical responses of two sugarcane varieties to whitefly Neomaskellia andropogonis Infestation and its control by a new butenolide insecticide, flupyradifurone. Agriculture and Forestry, 66 (1): 69-81.

DOI: 10.17707/AgricultForest.66.1.08

Zahra SAEEDI, Masumeh ZIAEE ${ }^{1}$

\title{
BIOCHEMICAL RESPONSES OF TWO SUGARCANE VARIETIES TO WHITEFLY NEOMASKELLIA ANDROPOGONIS INFESTATION AND ITS CONTROL BY A NEW BUTENOLIDE INSECTICIDE, FLUPYRADIFURONE
}

\begin{abstract}
SUMMARY
Sugarcane whitefly, Neomaskellia andropogonis Corbett (Homoptera: Aleyrodidae), is established in the sugarcane ecosystem of Khuzestan Province, and it is one of the most important pests of sugarcane. Two fields of the CP691062 and IRC99-02 varieties of sugarcane were selected for evaluation of their biochemical responses, including pigment content, nitrogen, total protein, phosphorus and soluble sugars, to $N$. andropogonis infestation. Also, the efficiency of a new butenolide insecticide, flupyradifurone, was assessed based on the population density of $N$. andropogonis.

The results indicate that infestation of $N$. andropogonis reduced the chlorophyll content, nitrogen and total protein of both examined varieties. In addition, flupyradifurone significantly decreased all life stages of $N$. andropogonis and the population density for 28 days after application the insecticide application. Furthermore, flupyradifurone did not adversely influence parasitic wasps ' activity in the parasitising nymphal stage of $N$. andropogonis. Based on our findings, the parasitism percentage reached $55.1 \%$ and $63.0 \%$ for the control and flupyradifurone-treated plots of IRC99-02, respectively, and $61.9 \%$ and $65.7 \%$ for the control and flupyradifurone-treated plots of CP69-1062, respectively.
\end{abstract}

Keywords: Control, field, insecticide, sugarcane, whitefly.

\section{INTRODUCTION}

Sugarcane (Saccharum species hybrids) is cultivated more in the tropics and subtropics and continues to be one of the most important industrial crops (James, 2004). Sugarcane is an important cash crop grown in Khuzestan region, Iran; So that more than 100,000 hectares of sugarcane are grown annually in this region (Nikpay \& Goebel, 2016). Different types of insect pests infest sugarcane

\footnotetext{
${ }^{1}$ Zahra Saeedi, Department of Plant Protection, Faculty of Agriculture, Shahid Chamran University of Ahvaz, Ahvaz, Iran; Masumeh Ziaee (corresponding author: m.ziaee@scu.ac.ir), Department of Plant Protection, Faculty of Agriculture, Shahid Chamran University of Ahvaz, Ahvaz, IRAN. Notes: The authors declare that they have no conflicts of interest. Authorship Form signed online. Received:29/10/2019

Accepted:10/01/2020
} 
which is categorized according to geographical distribution, taxonomic category, feeding habit, damage rate, etc. (Leslie, 2004).

Several species of whiteflies attack sugarcane. In Pakistan, Aleurolobus barodensis (Maskell) was more abundant whitefly than Neomaskellia andropogonis Corbett (Homoptera: Aleyrodidae) (Inayatullah, 1984); in Thailand A. barodensis (Charernsom \& Suasa-ard, 1989); and A. barodensis and N. bergii (Signoret) were reported from different states of India (Balikai et al., 1998; Vemuri et al., 2014). In Iran, N. andropogonis is the species of whitefly firstly reported by Askarianzadeh and Manzari (2006). In recent years, $N$. andropogonis has been considered as one of the important pests of sugarcane fields of Iran (Nikpay, 2017). The whitefly infested sugarcane stalks and leaves, sucking the sap and excretion of honeydew lead to sooty mold growth which reduces photosynthesis of sugarcane and result in more than 50\% yield losses (Nikpay, 2017; Srikanth et al., 2012). The ratoon crop of sugarcane is more sensitive and show severe damage by this pest (Masih et al., 1990; Srikanth et al., 2012); since ratoon crops produce more stalks per hectare than plant crops, however the stalks are usually not as thick and the growth of ratoon crops are weaker than planted canes (Vock, 2000). Damage of sugarcane whitefly not only prevents plant growth, but also reduced photosynthesis and chlorophyll content in sugarcane leaves lead to decreases in sugar content (Srikanth et al., 2012).

There are different methods for controlling whiteflies in sugarcane fields. Chemical control has always been the most effective way to reduce population of sugarcane whitefly (Chaudhary \& Jaipal, 2006; Koohzad-Mohammadi et al., 2017; Masih et al., 1990). Three insecticides have been evaluated by Masih et al. (1990) in Pakistan and Inexit 60EC was found to be more efficacious in controlling whitefly. Vijayaraghavan and Regupathy (2006) found thiamethoxam (200 g a.i) effectively reduced the population compared to dimethoate and imidacloprid. However, Bhavani and Rao (2013) findings indicated that the removal of infested leaves + spraying of imidacloprid was the most effective treatment for controlling A. barodensis population under filed conditions. In previous study, the toxicity of dinotefuran and deltamethrin were proved to be more than spiromesifen against $N$. andropogonis. However, spiromesifen had less adverse effects on pupal parasitism (Koohzad-Mohammadi et al., 2017).

Flupyradifurone (FPF), under the trade name Sivanto ${ }^{\circledR}$, is a new butenolide insecticide with fast contact toxicity, and feeding efficacy suitable for controlling insect vectors of virus like whiteflies and aphids. It functions as a partial agonist of postsynaptic AChRs and binds to insect nicotinic acetylcholine receptors (Jeschke et al., 2015).

The present study was conducted to 1) evaluate sugarcane whitefly damage on some biochemical properties of CP69-1062 and IRC99-02 varieties of sugarcane, 2) assess the effects of a new butenolide insecticide, flupyradifurone, to slow down the population density of sugarcane whitefly, $N$. andropogonis and 
to evaluate the efficacy of flupyradifurone on nymphal parasitism by parasitic wasps under natural field conditions.

\section{MATERIAL AND METHODS}

Sugarcane varieties: The experiments were carried out on two sugarcane varieties of CP69-1062 (Canal Point USA) and IRC99-02 (cross made in Cuba and selected in Iran) from October to November 2018. Two different fields with history of sugarcane whitefly infestation were chosen for the experiments. The fields were located at Salman Farsi Agro-industry farms (48 ${ }^{\circ} 35^{\prime} \mathrm{E}, 31^{\circ} 8 \mathrm{~S}$ ), Ahvaz, Iran. The conditions of the experiments were the same as described by (Koohzad-Mohammadi et al., 2017). Each experimental block (plot) consists of four rows, 15 meter long and 1.8 meter inter-row spaces (135-m2) in random places of each field. Before planting of sugarcane varieties, phosphorous fertilizer (Super phosphate triple/300 kg per hectare) was applied with a pneumatic fertilizer machine based on standard procedure of sugarcane nutrient treatments in Iran. Each sugarcane variety was planted as billets $(50-70 \mathrm{~cm}$ and free from stalk borers infestation) and following planting of seed cane sets all furrows were treated with Atrazine and Sencor herbicides ( $2+2 \mathrm{~kg}$ per hectare) based on local recommendations as early post emergence application for suppressing of annual weeds. During the crop growth all weeds in experimental plots removed manually by hand.

Biochemical properties estimation in sugarcane leaves infested by $N$. andropogonis: The infested leaves of CP69-1062 and IRC99-02 varieties of sugarcane were collected from Salman Farsi farms that were contaminated with $N$. andropogonis. Un-infested leaves were collected from the pest-free fields as control to evaluate the impact of whitefly damage on the content of some biochemical properties of sugarcane leaves. The leaves containing about 150 to 200 nymphs of sugarcane whitefly were considered as infested leaves. For each biochemical property, four replicates including four infested or un-infested leaves of both varieties were collected. The leaves were put into a plastic bag and transferred to the lab. At first, the infested or un-infested leaves were gently washed with distilled water and air-dried.

Chlorophyll content: The Chlorophyll content of four randomly selected plants from each variety was measured by the method of (Lichtenthaler, 1987). Based on this method, $0.1 \mathrm{~g}$ fresh leaf tissue weighed and $10 \mathrm{ml}$ acetone Merck $80 \%$ was added on the leaves. The leaves were well-rubbed and then $5 \mathrm{ml}$ acetone was added so that the final volume was $15 \mathrm{ml}$. The sample was centrifuged (SIGMA-D-37520 Osterode, Germany) for $20 \mathrm{~min}$ at $4000 \mathrm{rpm}$. Then the supernatant was obtained to measure chlorophyll a, b, carotenoid and total chlorophyll. Spectral absorption apparatus, UV 2100 Spectrophotometer, (Chemito Instruments Pvt. Ltd., Braunschweig, Germany) was used to estimate chlorophyll a, b, and carotenoid at wavelengths of $664.5 \mathrm{~nm}, 647 \mathrm{~nm}$ and 452.5 
nm, respectively. Acetone $80 \%$ was used as control (Blank). The pigments estimated in $\mathrm{mg} / \mathrm{g}$ wet weight of a plant leaf.

Nitrogen and total protein content: The nitrogen content of infested and uninfested leaves was determined by steam distillation using Kjeldahl digestion procedure. Crude protein content was measured by multiplying nitrogen content by a plant factor. The amount of nitrogen and protein were measured in milligrams per gram (mg/g) (AOAC International, 2006).

Phosphorus: Sugarcane leaves were dried at $70^{\circ} \mathrm{C}$ and analyzed for $\mathrm{P}$ content using UV 2100 Spectrophotometer (Chemito Instruments Pvt. Ltd., Braunschweig, Germany) at wavelength of $470 \mathrm{~nm}$.

Soluble sugar: The soluble sugar content was determined by the method of (Dubois et al., 1956). The whitefly infested and un-infested leaves were in an oven at $70^{\circ} \mathrm{C}$ and analyzed for soluble content using UV 2100 Spectrophotometer (Chemito Instruments Pvt. Ltd., Braunschweig, Germany) at wavelength of 490 $\mathrm{nm}$.

Insecticide formulation: Flupyradifurone (FPF) under the trade name Sivanto ${ }^{\circledR}$ (200 SL, Bayer CropScience, Germany) is a new insecticide from butenolide class register for controlling major sucking pests like aphids and whiteflies. Sivanto is agonist of nicotinic acetylcholine receptors. It is systemically translocate acropetally in the xylem, and is translaminarily distributed into the adjacent plant cells (Jeschke et al., 2015).

Field experiments: Experiments were carried out in Randomized Complete Block Design with four blocks (plants) and three replications (leaves). Flupyradifurone was applied on 6-October 2018 as soon as the population of whitefly eggs was observed in the fields. Foliar spraying was conducted in the early morning by a 15-litre volume sprayer (Hardi International, England).

Flupyradifurone was sprayed at the concentration of 0.3 lit/ha and untreated plots (water only spray) were considered as control. Sampling was made randomly and for each treatment, a total of 12 leaves were taken from the fields. Sampling was conducted before starting Sivanto application and 3 days, 1, 2, 3 and 4 weeks after spraying. The number of egg, nymph, pupae and adults of $N$. andropogonis per leaf and the number of parasitized pupae were recorded under stereomicroscope (Wild M3c, Heerbrugg Switzerland). The parasitized pupae are characterized by circular exit holes indicating emergence of parasitoid wasps.

Statistical analysis: All data were checked for normality using nonparametric Kolmogorov-Smirnov tests at $\mathrm{P}=0.01$. For the biochemical properties, mean comparison between control and infested leaves and also the comparison between two varieties, CP69-1062 and IRC99-02 was performed with t-test at $\mathrm{P}=0.01$.

The mortality data was transformed to square root of arcsine to normalize the data, but non-transformed data are presented in figures. The data from the fields were analyzed using Two-Way Analysis of Variance, with treatment 
(control and flupyradifurone) and exposure time as main effects. Differences among exposure times were separated using Tukey-Kramer honest test (HSD) and between control and flupyradifurone with student t-test at 0.05 significance levels using SPSS version 16 (SPSS, 2007).

\section{RESULTS AND DISCUSSION}

The results showed that in whitefly infested leaves, there was no significant difference in chlorophyll a content between CP69-1062 and IRC99-02 sugarcane varieties. The chlorophyll a content was 0.583 and $0.824 \mathrm{mg} / \mathrm{g}$ respectively. The chlorophyll a content in the control plots of IRC99-02 (1.48 mg/g) was significantly more than control of CP69-1062 (0.864 mg/g). Similar results were obtained in the chlorophyll b, carotenoid and total chlorophyll, and in all the greatest amount was recorded in un-infested leaves of IRC99-02 variety of sugarcane (Figure 1).
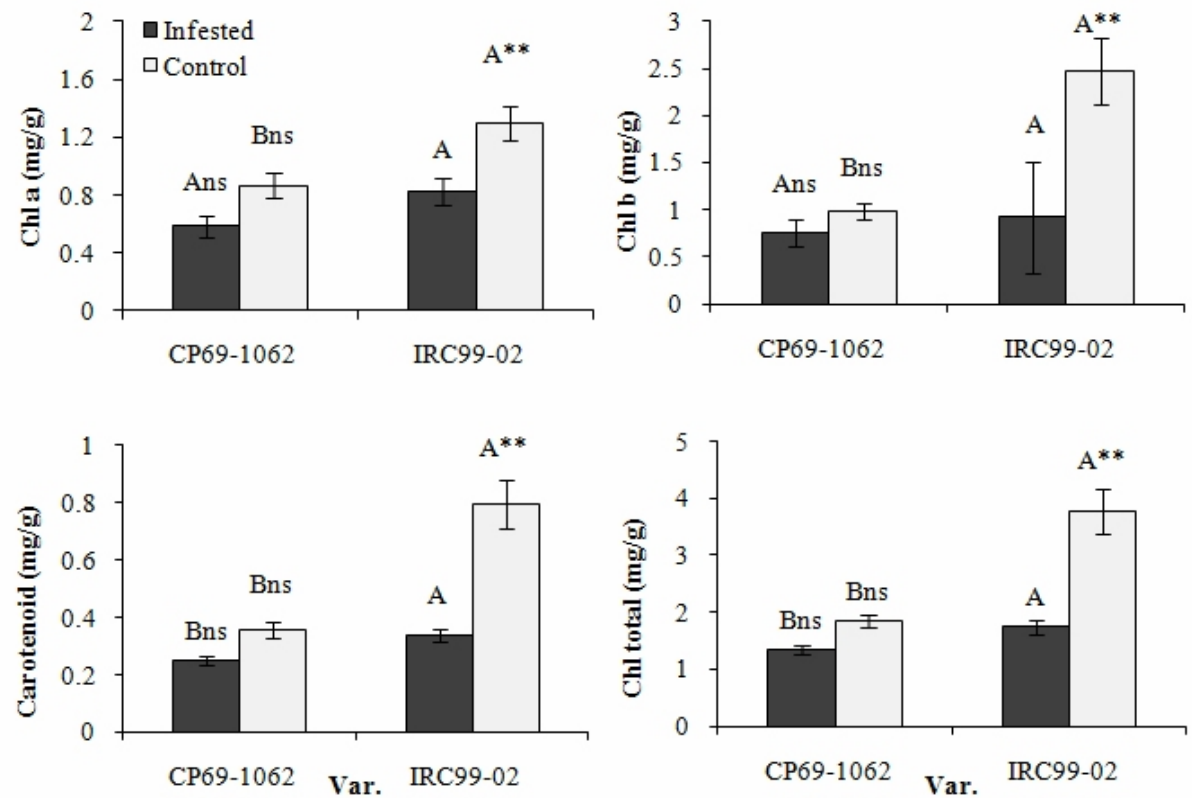

Figure 1: Mean content ( \pm SE) of pigments in sugarcane leaves infested by Neomaskellia andropogonis

ns: there was no significant difference between the infested and control leaves in each variety separately with ttest; ** there was a significant difference $(P=0.01)$. Means followed by the same upper case letters between two varieties were not statistically significant at $P=0.01$ with t-tes

There were not significant differences between varieties in nitrogen levels of the un-infested leaves, but it was significantly more than infested leaves. Comparable results were obtained for protein, and whitefly infestation significantly reduced the protein content of both varieties. In contrast, in both phosphorus and soluble sugar content, there were no significant differences neither between varieties nor infested and un-infested leaves (Figure 2). 
It was evident that the population density of all life stages of sugarcane whitefly was considerably higher in control than flupyradifurone treated leaves of CP69-1062 variety of sugarcane. However, for flupyradifurone in most cases the population was almost zero. For nymphal stage, an increasing trend in control was observed on 20 October which seems nymphs' population build up was slower on CP69-1062 than IRC99-02 variety. The pupal population of control plots reached to its peak level of 156 pupae per leaf on 27 October 2017 (Figure 3).

It was apparent that three days after foliar application of flupyradifurone, the egg population decreased and reached to 534 and 225 eggs per leaf for control and treated leaves, respectively. The highest nymphal population was observed on control plots of IRC99-02 variety in 13-October, while the population was low in flupyradifurone treatment at all sampling dates. The pupal population increased dramatically and reached to 214 pupae per leaf in 20 October and remained stable until 3 November (Figure 4).

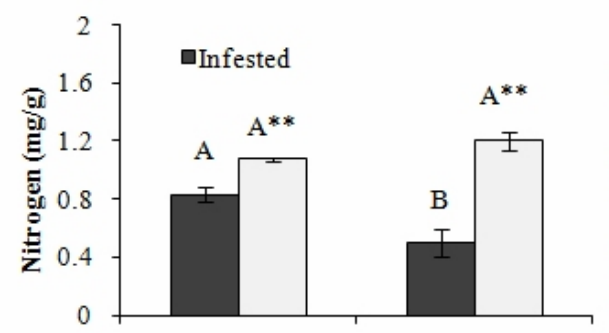

CP69-1062

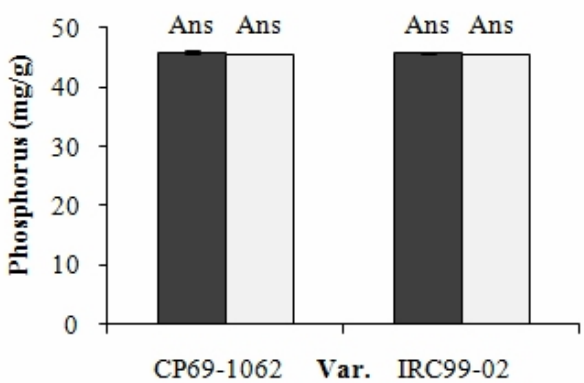

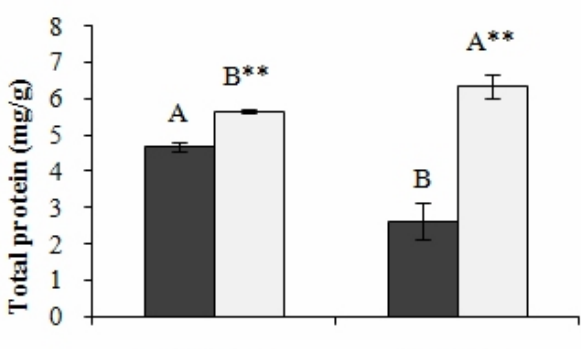

CP69-1062

IRC99-02

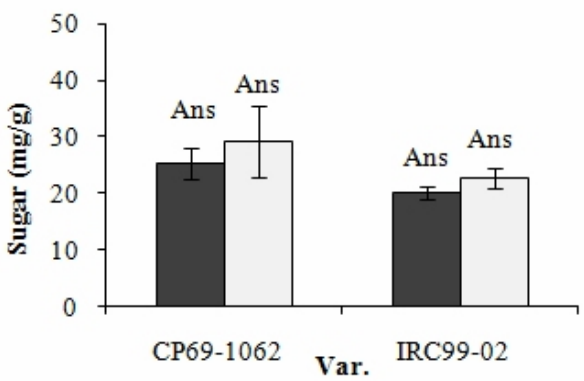

Figure 2: Mean $( \pm \mathrm{SE})$ of nitrogen, total protein, phosphorus and soluble sugars in sugarcane leaves infested by Neomaskellia andropogonis

ns: there was no significant difference between the infested and control leaves in each variety separately with ttest; ${ }^{* *}$ there was a significant difference $(P=0.01)$. Means followed by the same upper case letters between two varieties were not statistically significant at $P=0.01$ with t-test.

Flupyradifurone is recommended to control whiteflies and aphids with excellent speed of action to quick feeding cessation (Jeschke et al., 2015). In our study, the minimum population was recorded in flupyradifurone treated plots. This trend continued throughout the season, so that spraying flupyradifurone prevented whitefly population built up even after 28 days. 

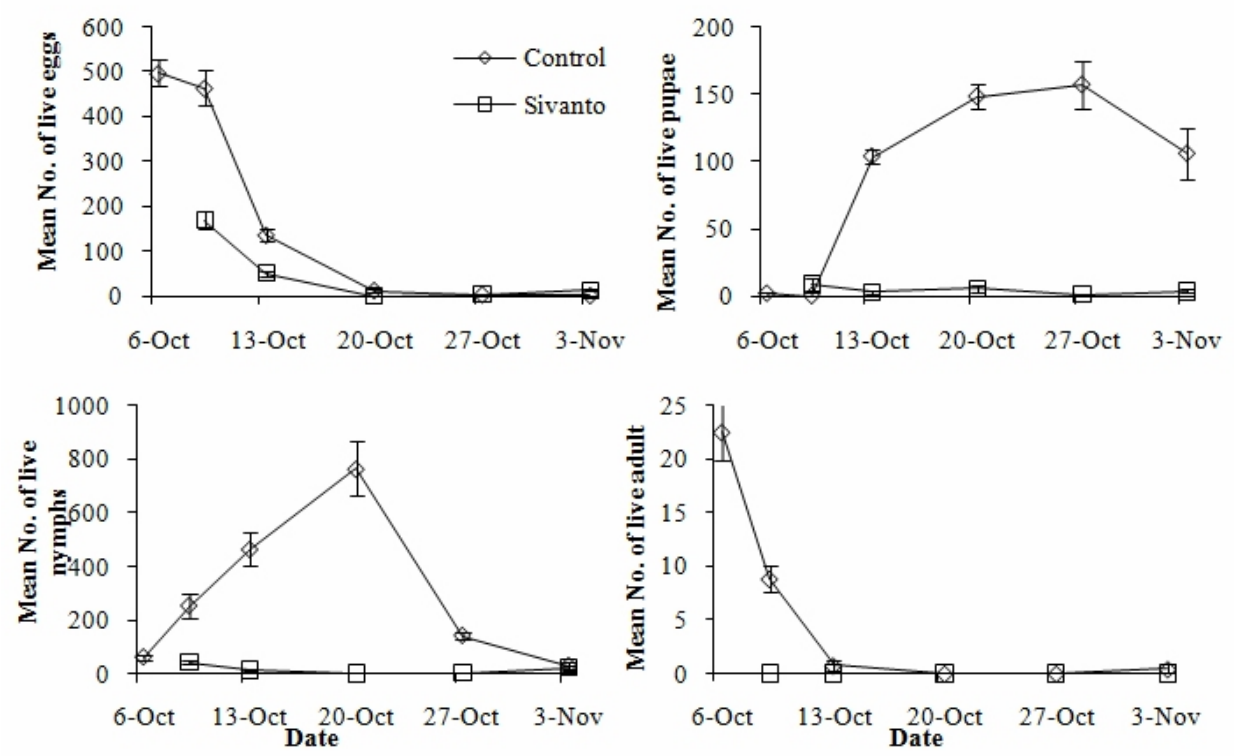

Figure 3: Population density of Neomaskellia andropogonis different life stages exposed to flupyradifurone on CP69-1062 variety of sugarcane.
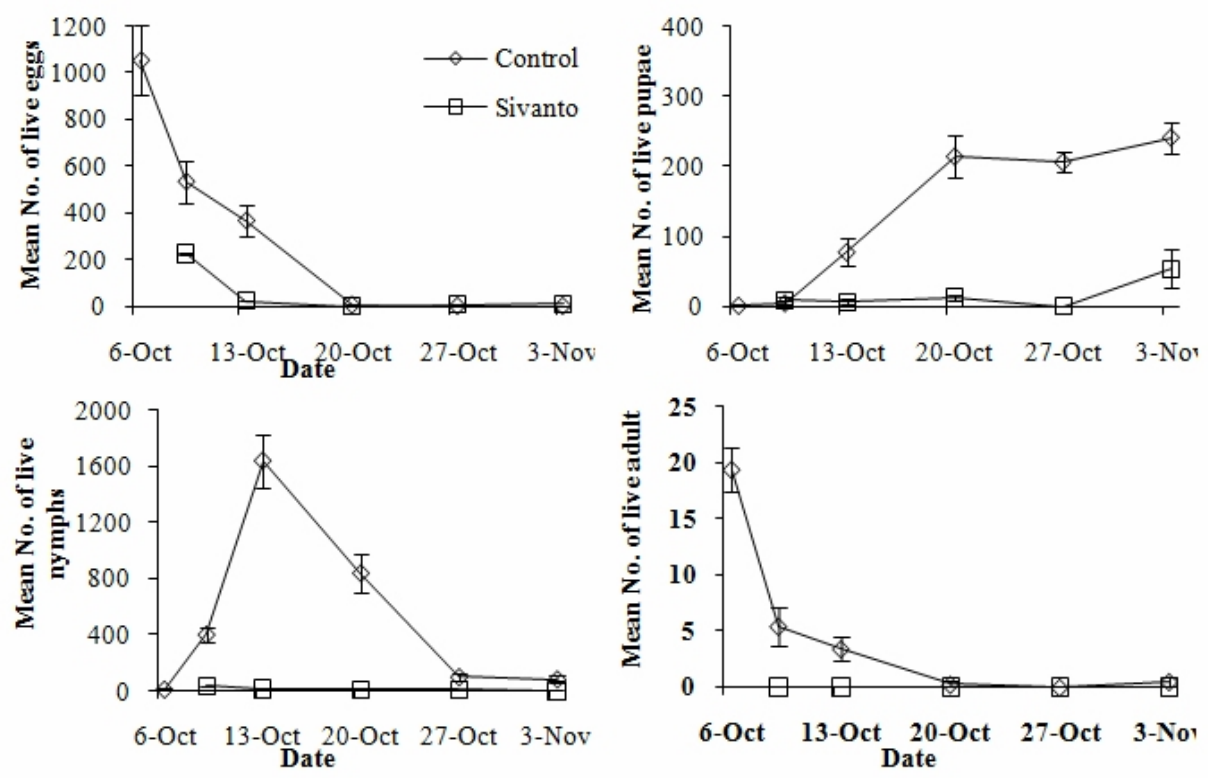

Figure 4: Population density of Neomaskellia andropogonis different life stages exposed to flupyradifurone on IRC99-02 variety of sugarcane. 
Nauen et al. (2015) reported flupyradifurone had a prominent effectiveness against sucking pests such as aphid and whitefly species with antifeedant activity and suppression of honeydew excretion.Flupyradifurone indicated higher toxicity against Lygus hesperus Knight (Hemiptera: Miridae) when compared with other insecticides including sulfoxaflor, flonicamid, thiamethoxam, fenpropathrin, essential oils (rosemary and peppermint oils), and mineral oil in commercial strawberry fields in 2014 and 2015 (Joseph \& Bolda, 2016).

Flupyradifurone provided control of whitefly eggs from $37.9 \%$ after 3 days to $100 \%$ after 14 days on CP69-1062 variety of sugarcane. Nymphal mortality was significantly higher $(<71 \%)$ in CP69-1062 variety treated with flupyradifurone than that of control. After 3 days of spraying flupyradifurone, $54.0 \%$ pupae were dead which increased to $90.0 \%$ after 21 days. Generally, adult mortality was $100 \%$ in leaves treated with flupyradifurone (Figure 5).

Mortality percentage for all life stages of $N$. andropogonis was almost zero in control plots of IRC99-02 variety. The percentage of egg mortality was 32.3\% after 3 days of flupyradifurone application but $90 \%$ mortality achieved after 7 days. The mortality of whitefly nymphs was recorded $68.5 \%$ after 3 days of the insecticide foliar application and significantly increased to $94 \%$ after 7 days. Mortality percentage of pupae was $51.0 \%$ after 3 days of flupyradifurone foliar application and increased significantly to $89.9 \%$ after 21 days. However, the efficacy of flupyradifurone declined 28 days after spraying on IRC99-02 variety of sugarcane. Complete mortality of $N$. andropogonis adults were recorded on flupyradifurone treated plots (Figure 6).

In both tested varieties, the nymphal parasitism percentage increased on $21^{\text {st }}$ day of sampling in control and flupyradifurone plots, which can be due to two reasons: 1 . the delayed appearance of parasitic wasps, or 2. absence of nymphs in the fields for parasitism. There was a significant difference between control and flupyradifurone in both varieties on $21^{\text {st }}$ day. However, the nymphal parasitism was raised over time after 28 days of the insecticide application (Figure 7).

Our results indicated that in both examined varieties, the sugarcane pigment contents, nitrogen and total protein was significantly reduced when infested by sugarcane whitefly. Buntin et al. (1993) stated that Bemisia tabaci (Gennadius) (Hemiptera: Aleyrodidae) infestation on tomato reduced the amount of photosynthesis. Although tomato plants has shown resistance by limiting stomatal aperture opening and gas exchanges, but the whitefly infestation reduced leaf chlorophyll content and photosynthesis capacity. Palumbo et al. (2000) declared that Bemisia argentifolii Bellows \& Perring feeding reduced the quality of and pure protein of alfalfa. In the other study, the infestations of B. tabaci on eggplant caused decrease in leaf area, leaf fresh weight, dry weight, chlorophyll content and photosynthesis rate. So that in infested leaves, the chlorophyll content and photosynthesis rate decreased by $9.7 \%$ and $65.9 \%$, respectively (Touhidul Islam \& Shunxiang, 2009). 

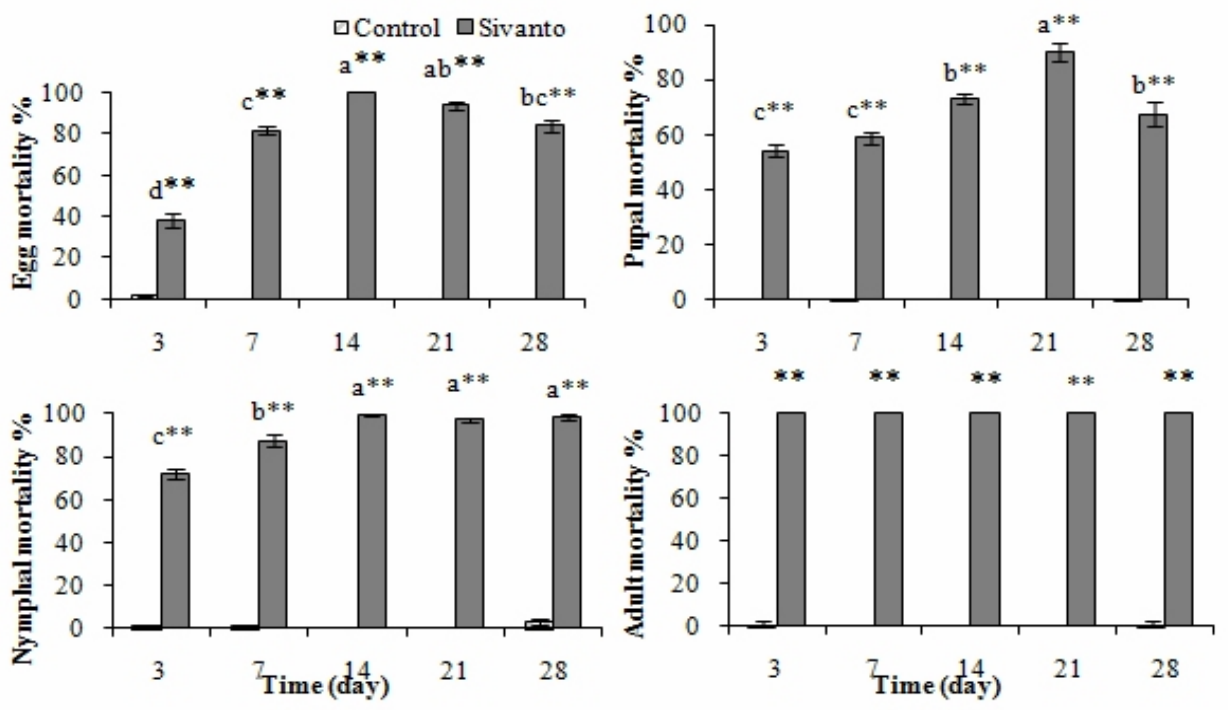

Figure 5: Mortality percentage ( \pm SE) of Neomaskellia andropogonis different life stages exposed to flupyradifurone on CP69-1062 variety of sugarcane.

Means followed by the same lower case letter among exposure times for Flupyradifurone are not significantly different using Tukey-Kramer (HSD) test at $P=0.05$. At each exposure time differences between control and

Flupyradifurone denoted with asterisk $(\mathrm{P}<0.01$, t-test, SPSS).
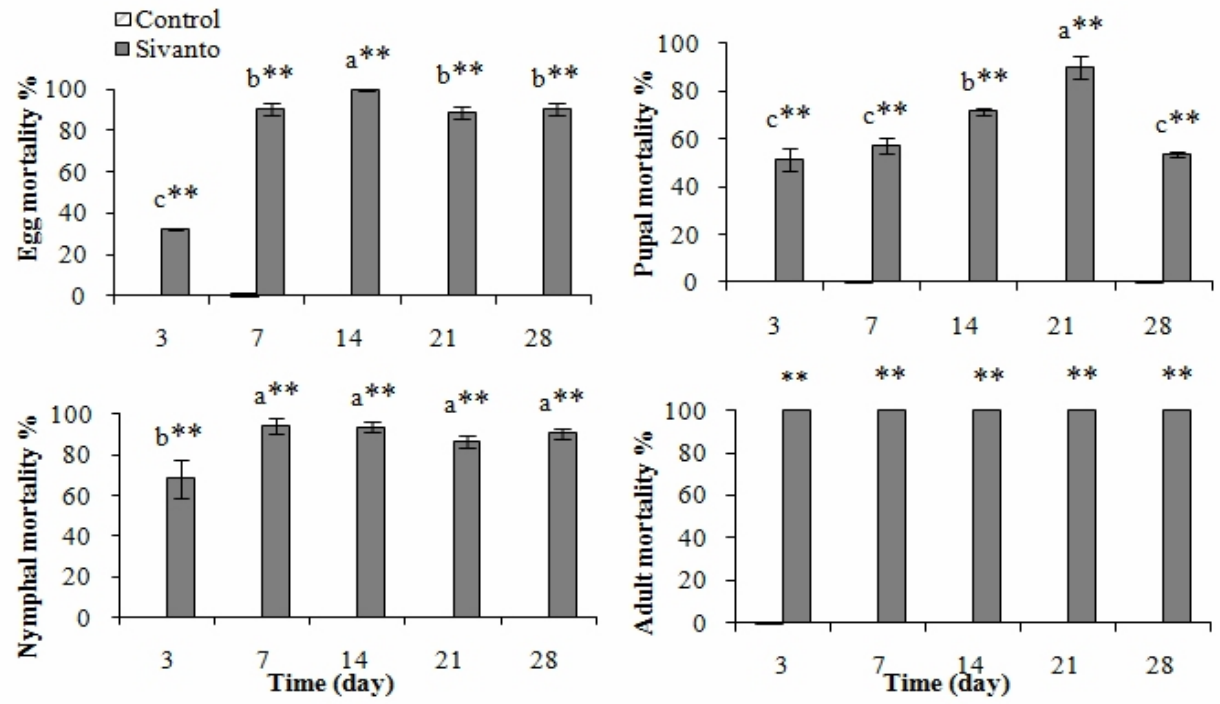

Figure 6: Mortality percentage ( \pm SE) of Neomaskellia andropogonis different life stages exposed to flupyradifurone on IRC99-02 variety of sugarcane risk ( $\mathrm{P}<$ 0.01 , t-test, SPSS).

Means followed by the same lower case letter among exposure times for Flupyradifurone are not significantly different using Tukey-Kramer (HSD) test at $P=0.05$. At each exposure time differences between control and Flupyradifurone denoted with asterisk ( $\mathrm{P}<0.01$, t-test, SPSS). 

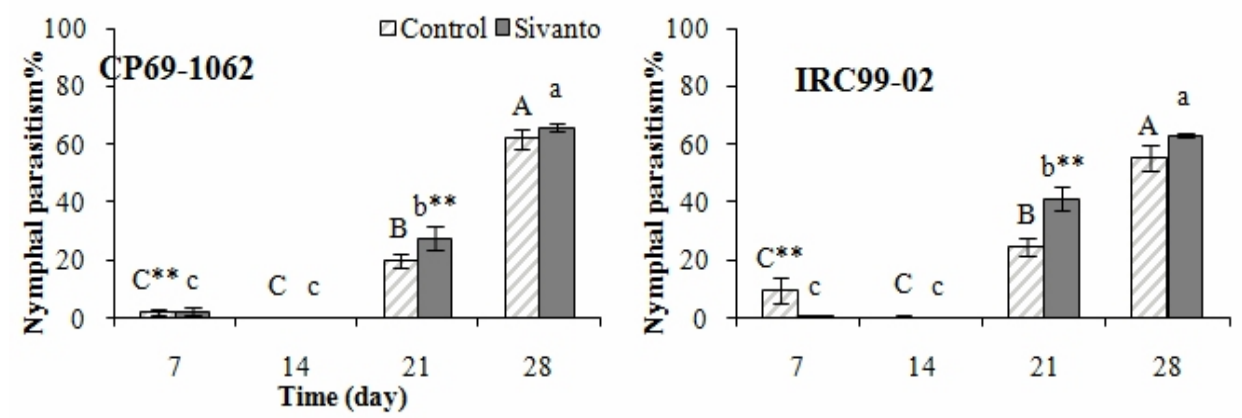

Figure 7: Nymphal parasitism percentage $( \pm \mathrm{SE})$ of Neomaskellia andropogonis exposed to flupyradifurone on CP69-1062 and IRC99-02 varieties of sugarcane.

Means followed by the same upper case letter for control and lower case letter for Flupyradifurone among exposure times are not significantly different using Tukey-Kramer (HSD) test at $P=0.05$. At each exposure time differences between control and Flupyradifurone denoted with asterisk $(\mathrm{P}<0.01$, t-test, SPSS).

Many studies have been carried out about the effect of $B$. tabaci on reduction of chlorophyll content of different plants such as cucumber, Cucumis sativus L. (Shannag \& Freihat, 2009), cucumbers, pumpkin, cantaloupe (AlShareef, 2011), tobacco, cotton (Li et al., 2013), and blackgram (Vigna mungo (L.) Hepper) (Taggar et al., 2015). Our results are in agreement with these reports and the chlorophyll content declined when leaves were attacked by sugarcane whitefly. However, to best of our knowledge there is not any published data about sugarcane whitefly, $N$. andropogonis effects on sugarcane.

Flupyradifurone was effective in reducing whitefly population density on sugarcane. These experiments under sugarcane field conditions demonstrated flupyradifurone can be a good alternative to synthetic insecticides that are currently used for controlling sugarcane whiteflies.

Control of sugarcane whitefly can also be performed by natural enemies such as parasitoids. In Iran, Encarsia inaron Walker (Hym.: Aphelinidae) (Malekmohammadi et al., 2012) and Eretmocerus delhiensis Mani (Hym.: Aphelinidae) (Khadempour et al., 2014) are reported as two main parasitic wasps of $N$. andropogonis suppressing the nymphal populations. Our results revealed that $E$. inaron and $E$. delhiensis provided significant suppression in sugarcane whitefly nymphs. The present findings agree with the results of Kumar et al. (2017a) who reported that the combination treatment of flupyradifurone with Eretmocerus eremicus Howard efficiently controlled Bemisia tabaci (Gennadius) (Hemiptera: Aleyrodidae) Mediterranean (MED) whitefly population. In the other research, Kumar et al. (2017b) emphasize the compatibility of flupyradifurone with swirskii mite, Amblyseius swirskii Athias-Henriot (Acari: Phytoseiidae) for the control of B. tabaci (MED). 


\section{CONCLUSIONS}

Flupyradifurone was effective in reducing all life stages of sugarcane whitefly population. The application of flupyradifurone with a delayed release of parasitic wasps is recommended to be applied as integrated pest management program (IPM) of $N$. andropogonis under field condition.

\section{ACKNOWLEDGEMENTS}

The authors are appreciated from Shahid Chamran University of Ahvaz for financial and logistic support of this project.

\section{REFERENCES}

Al-Shareef, L.A. (2011): Impact of whitefly, Bemisia tabaci (Gennadius) infestation on chlorophyl and carotene cocentrations, as well as moisure content in some vegetable plants in a greenhouse. The Egypt. J. Exp. Biol. (Zoo.) 7: 11-15.

AOAC International (2006): Official Methods of Analysis of AOAC International. Arlington: AOAC International.

Askarianzadeh, A. \& Manzari, S. (2006): Neomaskellia andropogonis (Hemiptera: Aleyrodidae), a new genus and species record for Iran. J. Entomol. Soci. Iran 26: 13-14.

Balikai, R., Lingappa, S., Biradar, A. \& Teggelli, R. (1998): Incidence of sugarcane whitefly in Karnataka. Karnataka J. Agric. Sci. 11: 820-821.

Bhavani, B. \& Rao, C.V.N. (2013): Management of sugarcane white fly (Aleurolobus barodensis Mask.) in North coastal districts of Andhra Pradesh, India. Int. J. Social Sci. Interdisciplinary Res. 2: 112-115.

Buntin, D.G., Gilbertz, D.A. \& Oetting, R.D. (1993): Chlorophyll loss and gas exchange in tomato leaves after feeding injury by Bemisia tabaci (Homoptera: Aleyrodidae). J. Econ. Entomol. 86: 517-522.

Charernsom, K., \& Suasa-ard, W. (1989): Sugarcane whitefly, Aleurolobus barodensis Maskell, and its parasites in Thailand. In Proc. XX Congress of the International Society of Sugar Cane Technologists: 769-802..

Chaudhary, O.P. \& Jaipal, S. (2006): Evaluation of new insecticides for controlling whitefly in sugarcane. Coop. Sugar 38: 37-40.

Dubois, M., Gilles, K.A., Hamilton, J.K., Rebers, P.t. \& Smith, F. (1956): Colorimetric method for determination of sugars and related substances. Analytical Chem. 28: 350-356.

Inayatullah, C. (1984): Sugar-cane aleurodids, Aleurolobus barodensis (Maskell) and Neomaskellia andropogonis Corbett (Hom.: Aleyrodidae), and their natural enemies in Pakistan. Insect Sci. its Applic. 5: 279-282.

James, G. (2004): Sugarcane. Second edn. Blackwell Publishing, London/ Britain.

Jeschke, P., Haas, M., Nauen, R., Gutbrod, O., Beck, M.E., Matthiesen, S. \& Velten, R. (2015): Sivanto ${ }^{\circledR}$-A novel insecticide with a sustainable profile: Discovery and Synthesis of Crop Protection Products. ACS Publications, American Chemical Society: Washington, DC, pp. 331-344.

Joseph, S.V. \& Bolda, M. (2016): Efficacy of Insecticides against Lygus hesperus Knight (Hemiptera: Miridae) in the California's Central Coast Strawberry. International Journal of Fruit Science 16: 178-187. 
Khadempour, A., Shishehbor, P., Rasekh, A. \& Evans, G. (2014): Report of the parasitoid wasp Eretmocerus delhiensis (Hym.: Aphelinidae) from Iran. J. Entomol. Soci. Iran 34: 17-18.

Koohzad-Mohammadi, P., Ziaee, M. \& Nikpay, A. (2017): Insecticides from different classes impact on Neomaskellia andropogonis population under sugarcane field conditions. Sugar Tech 19: 623-631.

Kumar, V., Houben, K., McKenzie, C.L. \& Osborne, L.S. (2017a): Efficacy of Eretmocerus eremicus and flupyradifurone on Bemisia tabaci (MED whitefly), 2017. Arthropod Manag. Tests. 42: tsx128.

Kumar, V., Kakkar, G., McKenzie, C.L. \& Osborne, L.S. (2017b): Efficacy of foliar application of flupyradifurone on Bemisia tabaci (MED Whitefly) and Amblyseius swirskii, 2017. Arthropod Manag. Test.s 42: tsx132.

Leslie, G. (2004): Pests of sugarcane: Sugarcane. In Gs James eds. Blackwell Science, Oxford/ Britain, pp. 78-100.

Li, Q., Tan, W., Xue, M., Zhao, H. \& Wang, C. (2013): Dynamic changes in photosynthesis and chlorophyll fluorescence in Nicotiana tabacum infested by Bemisia tabaci (Middle East-Asia Minor 1) nymphs. Arthropod-Plant Inte. 7: 431-443.

Lichtenthaler, H.K. (1987): Chlorophylls and carotenoids: pigments of photosynthetic biomembranes. Methods in enzymology 148: 350-382.

Malekmohammadi, A., Shishehbor, P. \& Kocheili, F. (2012): Influence of constant temperatures on development, reproduction and life table parameters of Encarsia inaron (Hymenoptera: Aphelinidae) parasitizing Neomaskellia andropogonis (Hemiptera: Aleyrodidae). Crop Protect. 34: 1-5.

Masih, R., Hashmi, A. \& Khan, N. (1990): Impact of controlling sugarcane whitefly on sugar recovery. Pakistan J. Agric. Res. 11: 271-274.

Nauen, R., Jeschke, P., Velten, R., Beck, M.E., Ebbinghaus-Kintscher, U., Thielert, W., Wölfel, K., Haas, M., Kunz, K. \& Raupach, G. (2015): Flupyradifurone: a brief profile of a new butenolide insecticide. Pest Manag. Sci. 71: 850-862.

Nikpay, A. (2017): Damage assessment of sugarcane whitefly Neomaskellia andropogonis Corbett and population dynamics on seven commercial varieties in Southwest of Iran. Sugar Tech 19: 198-205.

Nikpay, A., \& Goebel F.R. (2016): Major sugarcane pests and their management in Iran. In Proc. the International Society of Sugar Cane Technologists 29: 103-108.

Palumbo, J.C., Toscano, N.C., Blua, M.J. \& Yoshida, H.A. (2000): Impact of Bemisia whiteflies (Homoptera: Aleyrodidae) on alfalfa growth, forage yield, and quality. J. Econ. Entomol. 93: 1688-1694.

Shannag, H.K. \& Freihat, N.M. (2009): Gas exchange of cucumber, Cucumis sativus L., impaired by Tobacco Whitefly, Bemisia tabaci (Gennadius)(Hemiptera: Aleyrodidae). Jordan J. Agric. Sci. 5: 295-305.

SPSS (2007): SPSS 16 for Windows User's Guide Release: Spss Inc, Chicago

Srikanth, J., Salin, K. \& Jayanthi, R. (2012): Bioecology and management of pests: Sugarcane pests and their management. Sugarcane Breeding Institute, Indian Council of Agricultural Research, p. 88.

Taggar, G., Gill, R., Gupta, A. \& Singh, S. (2015): Bemisia tabaci (Gennadius) elicited leaf chlorophyll loss in blackgram (Vigna mungo (L.) Hepper). Food Legumes 28: 61-65. 
Touhidul Islam, M. \& Shunxiang, R. (2009): Effect of sweetpotato whitefly, Bemisia tabaci (Homoptera: Aleyrodidae) infestation on eggplant (Solanum melongena L.) leaf. J. Pest Sci. 82: 211-215.

Vemuri, S., Suresh, K. \& Kumar, M.V. (2014): Whitefly (Aleurolobus barodensis Mask.) population fluctuations in diverse conditions of sugarcane crop in Medak district of Andhra Pradesh, India. ZENITH Int. J. Multidisciplinary Res. 4: 217-221.

Vijayaraghavan, C. \& Regupathy, A. (2006): Bioefficacy of thiamethoxam (Actara 25WG) against sugarcane whitefly Aleurolobus barodensis Maskell. Int. J. Agric. Sci. 2: 299-304.

Vock, N. (2000): Sugarcane Advisors Information Kit, p. 134. 